\title{
Hematopoietic stem cell transplantation in children with Griscelli syndrome: A single-center experience
}

\author{
Baris Kuskonmaz $^{1}$ (D) | Deniz Ayvaz ${ }^{2}$ | Muge Gokce $^{3}$ | Tuba Turul Ozgur ${ }^{2}$ | \\ Fatma V. Okur ${ }^{1}$ | Mualla Cetin ${ }^{3}$ | Ilhan Tezcan ${ }^{2}$ | Duygu Uckan Cetinkaya ${ }^{1}$
}

${ }^{1}$ Division of Bone Marrow Transplantation, Department of Pediatrics, Hacettepe University Faculty of Medicine, Ankara, Turkey

${ }^{2}$ Division of Immunology, Department of Pediatrics, Hacettepe University Faculty of Medicine, Ankara, Turkey

${ }^{3}$ Division of Hematology, Department of Pediatrics, Hacettepe University Faculty of Medicine, Ankara, Turkey

\section{Correspondence}

Baris Kuskonmaz, Division of Bone Marrow Transplantation, Department of Pediatrics, Hacettepe University Faculty of Medicine, Ankara, Turkey.

Email: bkuskonmaz@gmail.com

\begin{abstract}
GS2 is a rare autosomal recessive disease characterized by hypopigmentation, variable immunodeficiency with HLH. HSCT is the only curative treatment for GS2. We analyzed the outcome of 10 children with GS2 who underwent HSCT at our center between October 1997 and September 2013. The median age of the patients at transplant was 13.5 months (range, 6-58 months). All of the patients developed HLH before HSCT and received HLH 94 or HLH 2004 protocols. Donors were HLA-identical relatives in 8 patients, HLA-mismatched relatives in 2 patients. Engraftment was achieved in all except one patient. None of the patients developed acute GVHD. Chronic GVHD occurred in one and veno-occlusive disease occurred in four patients. Eight of the patients are under remission without any neurologic sequelae-median time of disease-free survival is $\mathbf{9 2 . 4}$ months. The present study shows successful transplant outcome without long-term neurologic sequelae in patients with GS2 who underwent HSCT from HLA-related donors.
\end{abstract}

KEYWORDS

Griscelli syndrome, hemophagocytic lymphohistiocytosis, transplantation

\section{1 | INTRODUCTION}

GS2 is characterized by defective exocytosis of cytotoxic granules from $\mathrm{T}$ and natural killer cells leading to HLH in patients with GS2 which is known as "accelerated phase." ${ }^{1}$ Mutations in the gene encoding the small GTPase Rab27a lead to GS2. ${ }^{2}$ Immune defects, such as hypogammaglobulinemia, defect in natural killer cell and $T$ helper activity, diminished delayed-type skin hypersensitivity, and phagocytic defects are reported to be associated with GS2. ${ }^{3}$ In the first few years of life, HLH in these patients can be triggered by infections. ${ }^{4}$ The prognosis is very poor unless early allogeneic HSCT is carried out, preferably before the development of the accelerated phase. ${ }^{5}$ To date, only a few cases series of allogeneic HSCT in patients with GS2 have

Abbreviations: ATG, antithymocyte globulin; CC, complete chimerism; CR, complete remission; CsA, cyclosporine A; DFS, disease-free survival; EBV, Ebstein Barr virus; GS2, Griscelli syndrome type 2; GVHD, graft-versus-host disease; HLA, human leukocyte antigen; HLH, hemophagocytic lymphohistiocytosis; HSCT, hematopoietic stem cell transplantation; IVIG, intravenous immunoglobulin; OS, overall survival; PR, partial remission; $V O D$, veno-occlusive disease prophylaxis. been reported. ${ }^{5-7}$ The present study aimed to analyze the results of HSCT including survival rate, transplant complications, and neurologic outcome, performed in 10 patients with GS2 in a single center.

\section{2 | PATIENTS AND METHODS}

\section{1 | Patients}

Pretransplant features of the patients are shown in Table 1. GS2 was diagnosed with history, typical phenotypic features, microscopic examination of hair shafts, mutational analysis in the gene encoding small GTPase Rab27a and by development of HLH. Three patients had a sibling with GS2. History of parental consanguinity was present in eight patients. All patients were diagnosed during "accelerated phase," fulfilling at least five of the Histiocyte Society's criteria., Central nervous system involvement was evaluated by cerebrospinal fluid analysis and/or cranial imaging. The procedures applied in this study are in accordance with Helsinki Declaration of 1975. 
TABLE 1 Pretransplant characteristics of patients

\begin{tabular}{clllllll} 
Patient & $\begin{array}{l}\text { Age at diagnosis, } \\
\text { mo }\end{array}$ & Sex & Prior HLH & Neurologic findings & Prior therapy & $\begin{array}{l}\text { Disease status at } \\
\text { transplantation }\end{array}$ \\
\hline 1 & 46 & Female & Yes & $\begin{array}{c}\text { Strabismus, dysarthria, } \\
\text { ataxia }\end{array}$ & HLH-1994 & PR (HSMG) \\
\hline 2 & 2 & Female & Yes & Convulsion & HLH-1994 & NR & CR \\
\hline 3 & 3 & Male & Yes & - & HLH-1994 & PR (HMG) \\
\hline 4 & 3 & Male & Yes & - & HLH-1994 & CR \\
\hline 5 & 8 & Male & Yes & - & HLH-1994 & CR \\
\hline 7 & 24 & Female & Yes & - & HLH-2004 & PR (HSM, hyperferritinemia) \\
\hline 8 & 4 & Female & Yes & - & HLH-2004 & HLH-2004 & PR (SMG) \\
\hline 9 & 6 & Female & Yes & Convulsion & HLH-2004 & PR (HSMG) \\
\hline 10 & 5 & Male & Yes & - & HLH-2004 & PR (hyperlipidemia) \\
\hline
\end{tabular}

HLH, hemophagocytic lymphohistiocytosis; mo, months; PR, partial remission; HSMG, hepatosplenomegaly; NR, non-remission; CR, complete remission; HMG, hepatomegaly; SMG, splenomegaly.

\section{2 | Donor characteristics and source of stem cells}

The donors were HLA-identical sibling in six patients, HLA-identical father in two patients, HLA 1 antigen-mismatched mother in one patient, and HLA 1 antigen-mismatched other relative in one patient. The same donor was used in patient 2 for second and third transplantations. Bone marrow was used as the source of stem cells in seven patients, peripheral blood cells in two patients, and bone marrow and cord blood in one patient (Table 2). CD34 + selection or T-cell depletion was not performed in any patient.

\section{3 | Conditioning regimen and graft-versus-host disease prophylaxis}

Eight patients received conditioning regimen including busulfan (3.2-4 mg/kg/d intravenously or $4 \mathrm{mg} / \mathrm{kg} / \mathrm{d}$ orally for 4 days) $+\mathrm{cy}$ clophosphamide $(50 \mathrm{mg} / \mathrm{kg} / \mathrm{d}$ for 4 days) \pm antithymocyte globulin (ATG Fresenius $10 \mathrm{mg} / \mathrm{kg} / \mathrm{d}$ for 3 or 4 days)/etoposide $\left(900 \mathrm{mg} / \mathrm{m}^{2}\right.$ ), and two patients were given conditioning regimen including busulfan ( $4.8 \mathrm{mg} / \mathrm{kg} / \mathrm{d}-5.1 \mathrm{mg} / \mathrm{kg} / \mathrm{d}$ for 4 days) and fludarabine $\left(40 \mathrm{mg} / \mathrm{m}^{2} / \mathrm{d}\right.$ for 4 days). ATG was used as a part of conditioning regimen in the first six patients who underwent HSCT and was not used in the recently transplanted patients. Patient 2 underwent second and third transplantations with non-myeloablative conditioning regimens. Busulfan, cyclophosphamide, and etoposide were used as the conditioning regimen in the second transplantation; cyclophosphamide and etoposide were used in the third transplantation. CsA and short-term methotrexate were used as GVHD prophylaxis in all patients.

\section{4 | Supportive treatment}

All patients were hospitalized in single hepafiltered rooms until discharge. Acyclovir was given for herpes simplex virus and varicellazoster virus prophylaxis, fluconazole for fungal infection, and trimethoprim-sulfamethoxazole for pneumocystis jiroveci infection prophylaxis. Broad-spectrum antibiotic coverage was initiated with the first evidence of fever (axillary temperature $\max \geq 38^{\circ} \mathrm{C}$ ). IVIG was administered weekly at a dose of $400 \mathrm{mg} / \mathrm{kg}$ from the beginning of the conditioning regimen to discharge and then IVIG implementation was made according to serum IgG levels. Intravenous glutamine, low molecular weight heparin, ursodeoxycholic acid, and vitamin E were given for VOD. Defibrotide was also used for VOD prophylaxis in patients 9 and 10 who were recently transplanted.

\section{5 | Definitions}

OS was defined as survival from first HSCT to last follow-up or death. ${ }^{8}$ DFS was defined as the time from transplantation to first event (either relapse or death in complete remission). ${ }^{9}$ Primary graft failure defined as neutrophil never reaching $0.5 \times 10^{9} / \mathrm{L}$ or evidence of autologous reconstitution. ${ }^{10}$ Day of neutrophil engraftment was defined as the first of three consecutive days in which the peripheral absolute neutrophil count was $>0.5 \times 10^{9} / \mathrm{L}$. The presence of $>95 \%$ of donor-derived cells was defined as CC, while the presence of $>5 \%$ of host-derived cells was considered as mixed chimerism. ${ }^{11}$ Graft loss was defined by documentation of $<5 \%$ donor-derived engraftment. ${ }^{10}$ Patients who achieved engraftment and survived for more than 14 and 100 days post-transplantation were evaluated for acute and chronic GVHD, respectively. Conditioning regimens were categorized into myeloablative and non-myeloablative based on the American Society of Blood and Marrow Transplantation definitions. ${ }^{12}$ Presence of acute and chronic GVHD was determined according to the Seattle criteria. ${ }^{13,14}$ Acute GVHD was scored from day +1 and counted only for grades $\geq 2$. Diagnosis of hepatic VOD was made according to the Seattle criteria. ${ }^{15} \mathrm{CR}$ before HSCT was defined by the complete disappearance of the clinical and biological criteria of $\mathrm{HLH}$, and PR was defined as a significant improvement but with persistent clinical and/or biological manifestations according to the HLH 1994 criteria 


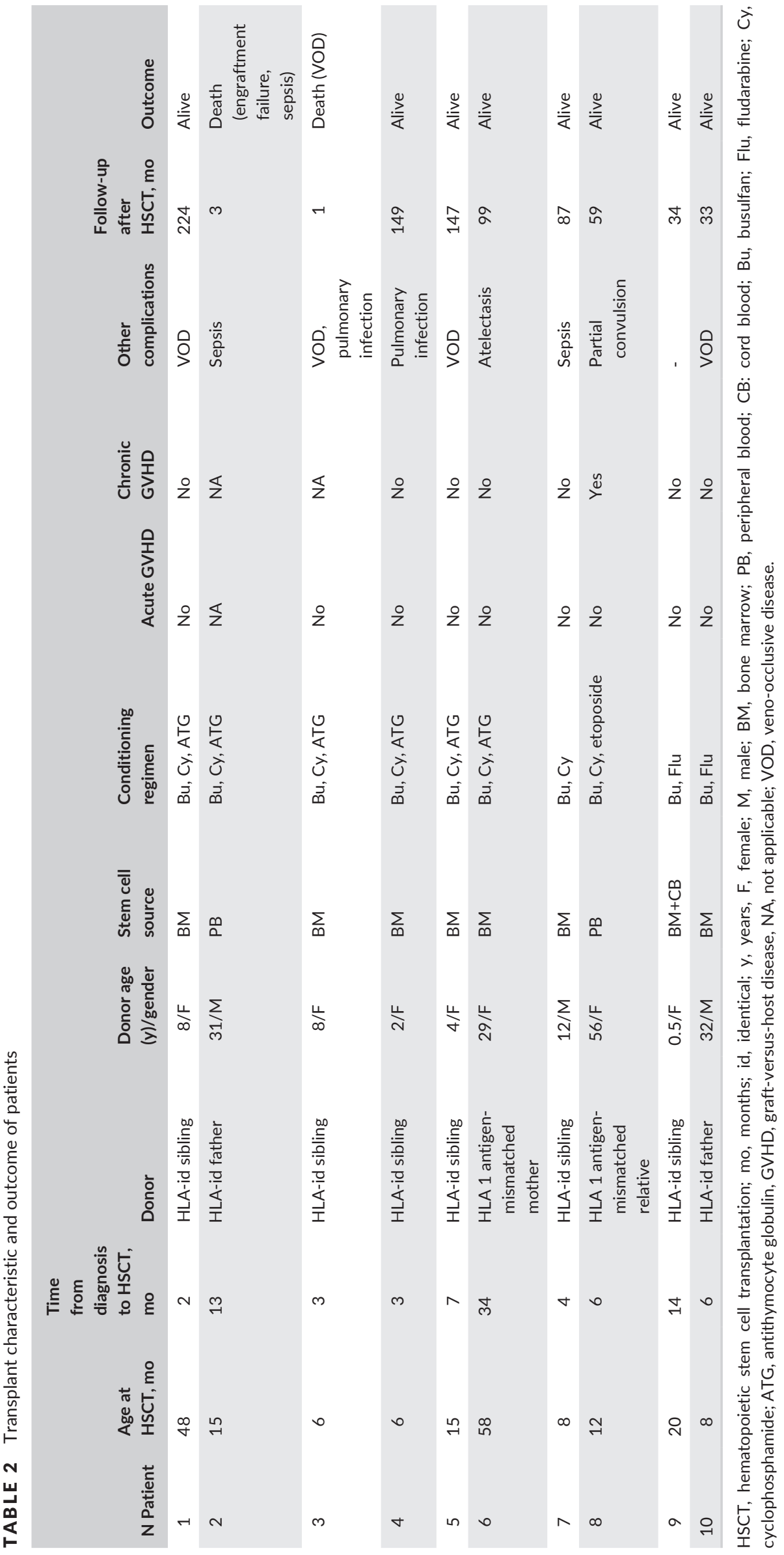


in the first five patients and according to the HLH 2004 criteria in the other five patients. ${ }^{16,17}$

\subsection{Statistical analysis}

Statistical analysis was performed using SPSS software, version 15.0. Descriptive statistics were generated as medians and ranges for continuous variables and proportions for categorical variables. The probability of overall survival was calculated using Kaplan-Meier analysis.

\section{3 | RESULTS}

Ten patients with GS2 underwent HSCT between October 1997 and September 2013 at our center (Table 1). The median age of the patients at transplant was 13.5 months (range, 6-58 months). Patient 2 underwent additional second and third transplantations due to primary graft failure. The median age of the patients at diagnosis was 6 months (range, 2-46 months). The median interval between diagnosis and HSCT was 6 months (2-34 months). HLH 94 protocol was used for the first five patients and HLH 2004 protocol was used for the other five patients. Complete remission was achieved in three patients and partial remission in six patients before HSCT. One patient (patient 2) had active disease at the time of HSCT (Table 1). Three patients (patient 1, patient 2, and patient 8 ) had neurologic involvement before HSCT. Two of them had convulsion and one had convulsion, strabismus, dysarthria, and ataxia.

\section{1 | Engraftment}

Neutrophil engraftment was obtained in all except one patient. The median time to neutrophil recovery was 13 days (range, 10-15 days). Patient 2 underwent second and third transplantations due to primary graft failure, but engraftment was not achieved after these transplantations. Patient 6 had $96 \%$ donor chimerism at day +20 ; however, donor chimerism gradually decreased in this patient ( $43 \%$ at +3 months, $38 \%$ at +6 months, $27 \%$ at +9 months, $15 \%$ at +15 months) resulting in graft loss. This patient survived without disease relapse for 99 months after transplant. Patient 7 who had full donor chimerism at +3 weeks after transplantation developed mixed chimerism during follow-up. This patient had $70 \%$ donor chimerism at last visit. All other surviving patients have full donor chimerism.

\subsection{Acute and chronic GVHD}

Nine of the 10 patients were evaluated for acute GVHD. Patient 2, who had graft failure, was not evaluated for acute GVHD. Acute GVHD was not observed in the remaining nine patients. Eight patients who had engraftment and survived more than 100 days after transplantation were assessed for chronic GVHD. Only one of these patients (patient 8) developed chronic GVHD with myasthenic symptoms including fatigue, difficulty in speech, bilateral ptosis, and dyspnea necessitating mechanical ventilation and treated with multiple immune-suppressive drugs and pyridostigmine. The patient recovered completely and did not experience any myasthenic symptom afterward.

\section{3 | Other complications}

VOD was observed in four patients and was the cause of death in patient 3. VOD resolved in the remaining three patients. Grade 3-4 mucositis developed in seven patients. Two patients developed sepsis, two had pulmonary infection, and one developed atelectasis. Partial convulsion was observed in patient 8 on day +6 . The cranial magnetic resonance imaging was normal except for decreased cerebral volume. Blood cyclosporine level was between 150 and $200 \mathrm{ng} / \mathrm{ml}$ which coincides with the targeted values. Electrolyte imbalance was not observed in this patient. An epileptic focus was not detected by electroencephalography. After switching CsA to tacrolimus, no convulsion was observed in this patient. No neurologic sequela was observed after HSCT in three patients who had neurologic findings before HSCT. Patient 1 developed melanotic skin lesions 2 years after HSCT. The lesions were removed surgically and the diagnosis of in situ melanoma was made histopathologically. Currently, the patient is well and is being followed up closely.

\section{4 | Survival}

Patient 2 died due to graft failure and infection on day +88 . Patient 3 developed VOD, consequently developed hepatic coma, and died on day +29 . The remaining 8 patients are alive without disease activation (median 92.4 months, range 33-224 months).

\section{4 | DISCUSSION}

HSCT is the only effective treatment in GS2. Most of the data about HSCT in GS2 in the literature are as case reports. ${ }^{18-22}$ Three case series are reported to date, the largest involving 11 patients. ${ }^{5-7}$ In our study, we analyzed the results of HSCT in 10 GS2 patients. In the series reported by Pachlopnik Schimid et al, ${ }^{6}$ seven of 10 patients had recovered (mean follow-up period 5.2 years). Three patients had died within 110 days after HSCT. Deaths were caused by EBV-related lymphoproliferative disease in one patient and respiratory distress syndrome in two patients in that series. ${ }^{6}$ In another study including 11 patients, all except one were reported to survive. ${ }^{5}$ Median follow-up period was $\mathbf{5 7 . 6}$ months in this study mentioned above. ${ }^{5}$ In a smaller series of five patients who underwent HSCT with reduced intensity regimen, four were reported to be alive at the end of a median followup period of 19 months. $^{7}$ One patient who was at the accelerated phase at the time of HSCT was reported to relapse after 3 months, and died of sepsis and intracranial hemorrhage. ${ }^{7}$ In our study, survival rate was found as $80 \%(8 / 10)$ and all patients achieved DFS. Several studies have documented the outcome of HSCT with myeloablative regimens in other $\mathrm{HLH}$ groups with overall long-term survival ranging from $45 \%$ to $65 \% .{ }^{11,23-26}$ Cooper et al ${ }^{27}$ reported an improved survival rate with non-myeloablative conditioning (75\%) in a group of 12 
patients with familial $\mathrm{HLH}, \mathrm{X}$-linked lymphoproliferative $\mathrm{P}$ disease, and Chediak-Higashi syndrome. Optimal conditioning regimen for HSCT in primary immunodeficiency has yet to be defined. ${ }^{28}$ Myeloablative regimen has a higher rate of toxicity and long-term complications including infertility and secondary malignancies. ${ }^{29,30}$ Non-myeloablative conditioning regimen might be a reasonable option for most patients due to significant pretransplant morbidity. ${ }^{31,32}$ However, there is also a higher risk of mixed donor chimerism as well as a high rate of viral reactivation as part of non-myeloablative conditioning regimen. ${ }^{28}$

Graft failure in HSCT in patients with active HLH was previously reported in the literature. ${ }^{33,34}$ Primary graft failure was observed in one patient in our study. This patient was in the active phase of disease at the time of HSCT. This patient underwent second and third HSCTs due to graft failure, however died on day +88 because of infection and graft failure. Cytokines secreted during active phase of the disease were shown to inhibit hematopoiesis in murine models which probably explains the cause of graft failure. ${ }^{35}$ Therefore, for a successful result, HSCT should be made during remission of primary disease if possible.

VOD is a potentially mortal complication of HSCT with a reported incidence ranging from $5 \%$ to $60 \%{ }^{36}$ This variation is related to the intensity of conditioning regimen, type of transplant (higher with allogeneic when compared to autologous HSCT), and presence of other risk factors as well as the variation in the clinical criteria used to define VOD. In the pediatric setting, the risk of VOD is higher in some diseases including $\mathrm{HLH}$ and in younger patients under 1-2 years of age. ${ }^{37-40}$ In our series, all patients received a myeloablative regimen and all except two were under the age of 2 at the time of HSCT. In the study by Pachlopnik Schimid et al, ${ }^{6}$ five of ten patients with GS2 were reported to develop VOD. In our series, four of ten patients developed VOD and one of them died of this complication. Several drugs have been used in the pharmacological prevention of VOD including ursodeoxycholic acid, vitamin E, low molecular weight heparin, and dipeptiven. ${ }^{36,41}$ However, the success of these prophylactic agents was suboptimal. Some recent studies have shown that defibrotide is an effective agent in the prophylaxis of VOD in HSCT patients. ${ }^{42,43} \mathrm{We}$ used defibrotide in the last two patients and one of them developed mild VOD.

Although full donor chimerism was observed immediately after transplantation in patient 7 , mixed chimerism developed in time (70\% donor profile in the latest follow-up visit); nevertheless, DFS was achieved. In patient 6 , full donor chimerism was observed at day +21; however, donor chimerism gradually decreased and eventually resulted in graft loss. However, disease relapse is not observed in this patient during follow-up. Remission of GS2 after HSCT even with lowlevel donor chimerism is reported in the literature. ${ }^{44} \mathrm{~A}$ recent study showed that a donor chimerism of $20 \%-30 \%$ is enough to protect against HLH recurrence. The authors of this article emphasize the key role of T cells in HLH pathogenesis and suggest separate analysis of CD $3+$ lymphocytes. ${ }^{45}$ The rate of CD3 + cell engraftment may be higher in our patient; however, T-cell engraftment was not studied.

Although myeloablative conditioning regimens, which are a risk factor for acute GVHD, ${ }^{46}$ were used in our series, no patients developed acute GVHD. In the series by Pachlopnik Schimid et al, ${ }^{6}$ seven of ten patients with GS2 were reported to develop acute GVHD. In this study, only 3 donors were HLA-identical siblings. On the other hand, Al-Ahmari et al ${ }^{5}$ reported only 3 patients with grade I-II acute GVHD in their series of eleven patients; 8 of the donors were HLA-identical siblings in this series. HLA incompatibility between patient and donor is the major risk factor for acute GVHD. In addition, GVHD risk is higher in unrelated donors when compared to related donors. ${ }^{46,47}$ In our series, eight patients had full-matched related donors and two had one mismatched related donors. Using peripheral blood as a stem cell source instead of bone marrow in HSCT is another factor associated with a higher incidence of severe acute GVHD. ${ }^{46,48}$ In 8 of 10 transplantations, bone marrow is used as a stem cell source. One of our patients developed chronic GVHD manifesting as a very rare clinical situation: myasthenia gravis. This case was previously reported in the literature. ${ }^{49}$

The frequency of neurologic involvement in HLH varies in the literature. In the series by Pachlopnik Schimid et al, ${ }^{6}$ neurologic involvement was reported in seven of 10 patients prior to HSCT. Three of them died. In that study, neurologic symptoms were reported to have resolved with HSCT in two patients and have persisted after HSCT in two. ${ }^{6} \mathrm{Al}$-Ahmari et al ${ }^{5}$ reported neurologic involvement in seven of 11 patients prior to HSCT. In this series, neurologic problems were observed in three patients after HSCT. In the case series involving five patients who underwent HSCT for GS2, none of the patients were reported to have neurologic involvement prior to transplantation. ${ }^{7}$ In our study, three patients had neurologic findings prior to HSCT. One of our patients (patient 8) had a neurologic complication presenting as convulsions after HSCT. This may be related either to CSA toxicity or to the underlying primary disease of the patient. ${ }^{5,6,50}$ No other neurologic complications were observed after HSCT and neurologic findings in the patients with known prior neurologic involvement did not progress either.

In the long-term follow-up of the patients, patient 1 developed in situ melanoma 2 years after HSCT, which was successfully treated with surgical excision. This case was previously reported. ${ }^{51}$ Following $\mathrm{HSCT}$, an increased risk of secondary malignancies including skin cancer is well known. Data about skin cancer following HSCT are mostly derived from case reports, but five large studies have reported an increased incidence of melanoma after allogeneic HSCT compared with the general population. ${ }^{52,53}$

In conclusion, in this single-center study from Turkey, longterm survival was achieved in eight of ten patients who underwent HSCT for GS 2. None of our patients developed acute GVHD. HLAmatched sibling or family donors reduce the incidence of acute GVHD. No permanent neurologic disease was observed in our patients. According to results of the present study, we can conclude that HSCT had no effect on neurologic symptoms of GS2. Mixed chimerism may be sufficient for preventing HLH in these patients. Interestingly, one patient who had graft loss after HSCT is still being followed up without disease relapse. We suggest performing HSCT while the primary disease is in remission in order to achieve a successful engraftment. 


\section{ACKNOWLEDGMENTS}

We are grateful to the nurses of Bone Marrow Transplantation Unit for their priceless efforts in care of our patients.

\section{CONFLICT OF INTEREST}

The authors declare no conflict of interest.

\section{REFERENCES}

1. Menasche G, Feldmann J, Fischer A, de Saint Basile G. Primary hemophagocytic syndromes point to a direct link between lymphocyte cytotoxicity and homeostasis. Immunol Rev. 2005;203:165-179.

2. Menasche G, Feldmann J, Fischer A, et al. Mutations in Rab27a cause Griscelli syndrome associated with hemophagocytic syndrome. Nat Genet. 2000;25:173-176.

3. Haddad EK, Wu X, Hammer JA, Henkart PA. Defective granule exocytosis in Rab27A deficient lymphocytes from ashen mice. J Cell Biol. 2001;152:835-841.

4. Kumar M, Sackey K, Schmalstieg F, Trizna Z, Elghetany MT, Alter BP. Griscelli syndrome: a rare neonatal syndrome of recurrent hemophagocytosis. J Pediatr Hematol Oncol. 2001;23:464-468.

5. Al-Ahmari A, Al-Ghonaium A, Al-Mansoori M, et al. Hematopoietic SCT in children with Griscelli syndrome: a single-center experience. Bone Marrow Transplant. 2010;45:1294-1299.

6. Pachlopnik Schmid J, Moshous D, Boddaert N, et al. Hematopoietic stem cell transplantation in Griscelli syndrome type 2: a single-center report on 10 patients. Blood. 2009;114:211-218.

7. Hamidieh AA, Pourpak Z, Yari K, et al. Hematopoietic stem cell transplantation with a reduced-intensity conditioning regimen in pediatric patients with Griscelli syndrome type 2. Pediatr Transplant. 2013;17:487-491.

8. Lum SH, Miller WP, Jones S, et al. Changes in the incidence, patterns and outcomes of graft failure following hematopoietic stem cell transplantation for Hurler syndrome. Bone Marrow Transplant. 2017;56:846-853

9. Canaani J, Savani BN, Labopin M, et al. Impact of ABO incompatibility on patient outcome in haploidentical hematopoietic stem cell transplantation for acute myeloid leukemia - a report from the acute leukemia working party of the EBMT. Haematologica. 2017;102: 1066-1074.

10. Shekhovtsova Z, Bonfim C, Ruggeri A, et al. A risk factor analysis of outcomes after unrelated cord blood transplantation for children with Wiskott-Aldrich syndrome. Haematologica. 2017;102:1112-1119.

11. Fu L, Wang J, Wei N, et al. Allogeneic hematopoietic stem-cell transplantation for adult and adolescent hemophagocytic lymphohistiocytosis: a single center analysis. Int J Hematol. 2016;104: 628-635.

12. Bacigalupo A, Ballen K, Rizzo D, et al. Defining the intensity of conditioning regimens: working definitions. Biol Blood Marrow Transplant. 2009;15:1628-1633.

13. Glucksberg $\mathrm{H}$, Storb R, Fefer A, et al. Clinical manifestations of graft versus-host disease in human recipients of marrow from HLAmatched sibling donors. Transplantation. 1974;18:295-304.

14. Storb R, Prentice RL, Sullivan KM, et al. Predictive factors in chronic graft versus-host disease in patients with aplastic anemia treated by bone marrow transplantation from HLA-identical siblings. Ann Intern Med. 1983;98:461-466.

15. McDonald GB, Sharma P, Matthews DE, Shulman HM, Thomas ED. Venocclusive disease of the liver after bone marrow transplantation: diagnosis, incidence, and predisposing factors. Hepatology. 1984:4:116-122.
16. Henter JI, Samuelsson-Horne A, Aricò M, et al. Treatment of hemophagocytic lymphohistiocytosis with HLH-94 immunochemotherapy and bone marrow transplantation. Blood. 2002;100:2367-2373.

17. Henter JI, Horne A, Aricó M, et al. Diagnostic and therapeutic guidelines for hemophagocytic lymphohistiocytosis. Pediatr Blood Cancer. 2007;48:124-131.

18. Tezcan I, Sanal O, Ersoy F, et al. Successful bone marrow transplantation in a case of Griscelli disease which presented in accelerated phase with neurological involvement. Bone Marrow Transplant. 1999;24:931-933.

19. Baumeister F, Stachel D, Schuster F, et al. Accelerated phase in partial albinism with immunodeficiency (Griscelli syndrome): genetics and stem cell transplantation in a 2-month-old girl. Eur J Pediatr. 2000;159:74-78.

20. Schuster F, Stachel DK, Schmid I, et al. Griscelli syndrome: report of the first peripheral blood stem cell transplant and the role of mutations in the RAB27A gene as an indication for BMT. Bone Marrow Transplant. 2001;28:409-412.

21. Aricò M, Zecca M, Santoro N, et al. Successful treatment of Griscelli syndrome with unrelated donor allogeneic hematopoietic stem cell transplantation. Bone Marrow Transplant. 2002;29:995-998.

22. Rossi A, Borroni RG, Carrozzo AM, et al. Griscelli syndrome type 2 : long-term follow-up after unrelated donor bone marrow transplantation. Dermatology. 2009;218:376-379.

23. Horne A, Janka G, Maarten Egeler R, et al. Haematopoietic stem cell transplantation in haemophagocytic lymphohistiocytosis. $\mathrm{Br} J$ Haematol. 2005;129:622-630.

24. Ouachée-Chardin M, Elie C, de Saint Basile G, et al. Hematopoietic stem cell transplantation in hemophagocytic lymphohistiocytosis: a single-center report of 48 patients. Pediatrics. 2006;117:e743-e750.

25. Baker KS, Filipovich AH, Gross TG, et al. Unrelated donor hematopoietic cell transplantation for hemophagocytic lymphohistiocytosis. Bone Marrow Transplant. 2008;42:175-180.

26. Ohga S, Kudo K, Ishii E, et al. Hematopoietic stem cell transplantation for familial hemophagocytic lymphohistiocytosis and EpsteinBarr virus-associated hemophagocytic lymphohistiocytosis in Japan. Pediatr Blood Cancer. 2010;54:299-306.

27. Cooper N, Rao K, Gilmour K, et al. Stem cell transplantation with reduced-intensity conditioning for hemophagocytic lymphohistiocytosis. Blood. 2006;107:1233-1236.

28. Cuellar-Rodriguez J, Freeman AF, Grossman J, et al. Matched related and unrelated donor hematopoietic stem cell transplantation for DOCK8 deficiency. Biol Blood Marrow Transplant. 2015;21:1037-1045.

29. Tichelli A, Rovó A. Fertility issues following hematopoietic stem cell transplantation. Expert Rev Hematol. 2013;6:375-388.

30. Adhikari J, Sharma P, Bhatt VR. Risk of secondary solid malignancies after allogeneic hematopoietic stem cell transplantation and preventive strategies. Future Oncol. 2015;11:3175-3185.

31. Al-Mousa H, Hawwari A, Alsum Z. In DOCK8 deficiency donor cell engraftment post-genoidentical hematopoietic stem cell transplantation is possible without conditioning. J Allergy Clin Immunol. 2013;131:1244-1245.

32. Ghosh S, Schuster FR, Fuchs I, Laws HJ, Borkhardt A, Meisel R. Treosulfan-based conditioning in DOCK8 deficiency: complete lympho-hematopoietic reconstitution with minimal toxicity. Clin Immunol. 2012;145:259-261.

33. Hege K, Quigg T, Delgado D. Alemtuzumab, Fludarabine, Low-Dose $\mathrm{TBI}$, and Double Umbilical Cord Transplant for Primary Graft Failure in a Patient with Recurrent HLH. Pediatr Blood Cancer. 2016;63:361-363.

34. Feldmann J, Le Deist F, Ouachee-Chardin M, et al. Functional consequences of perforin gene mutations in 22 patients with familial haemophagocytic lymphohistiocytosis. BrJ Haematol. 2002;117:965-972.

35. Rottman M, Soudais C, Vogt G, et al. IFN- $\gamma$ mediates the rejection

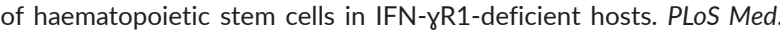
2008;5:e26. 
36. Mohty M, Malard F, Abecassis M, et al. Sinusoidal obstruction syndrome/veno-occlusive disease: current situation and perspectives-a position statement from the European Society for Blood and Marrow Transplantation (EBMT). Bone Marrow Transplant. 2015;50:781-789.

37. Coppell JA, Richardson PG, Soiffer R, et al. Hepatic veno-occlusive disease following stem cell transplantation: incidence, clinical course, and outcome. Biol Blood Marrow Transplant. 2010;16:157-168.

38. Carreras E. How I manage sinusoidal obstruction syndrome after haematopoietic cell transplantation. Br J Haematol. 2015;168:481-491.

39. Cesaro S, Pillon M, Talenti E, et al. A prospective survey on incidence, risk factors and therapy of hepatic veno-occlusive disease in children after hematopoietic stem cell transplantation. Haematologica. 2005;90:1396-1404.

40. Cheuk DK, Wang P, Lee TL, et al. Risk factors and mortality predictors of hepatic veno-occlusive disease after pediatric hematopoietic stem cell transplantation. Bone Marrow Transplant. 2007;40:935-944.

41. Senzolo M, Germani G, Cholongitas E, Burra P, Burroughs AK. Veno occlusive disease: update on clinical management. World J Gastroenterol. 2007;13:3918-3924.

42. Chalandon Y, Roosnek E, Mermillod B, Newton A, Ozsahin H, Wacker P. Prevention of veno-occlusive disease with defibrotide after allogeneic stem cell transplantation. Biol Blood Marrow Transplant. 2004;10:347-354.

43. Corbacioglu S, Kernan N, Lehmann L, et al. Defibrotide for the treatment of hepatic veno-occlusive disease in children after hematopoietic stem cell transplantation. Expert Rev Hematol. 2012;5:291-302.

44. Landman-Parker J, Le Deist F, Blaise A, Brison O, Fischer A. Partial engraftment of donor bone marrow cells associated with long-term remission of haemophagocytic lymphohistiocytosis. $\mathrm{Br} J$ Haematol. 1993;85:37-41.

45. Hartz B, Marsh R, Rao K, et al. The minimum required level of donor chimerism in hereditary hemophagocytic lymphohistiocytosis. Blood. 2016;127:3281-3290.

46. Harris AC, Ferrara JL, Levine JE. Advances in predicting acute GVHD. Br J Haematol. 2013;160:288-302.
47. Baron F, Mohty M, Blaise D, et al. Anti-thymocyte globulin as graftversus-host disease prevention in the setting of allogeneic peripheral blood stem cell transplantation: a review from the Acute Leukemia Working Party of the European Society for Blood and Marrow Transplantation. Haematologica. 2017;102:224-234.

48. Holtan SG, MacMillan ML. A risk-adapted approach to acute GVHD treatment: are we there yet? Bone Marrow Transplant. 2016;51:172-175

49. Unal S, Sag E, Kuskonmaz B, et al. Successful treatment of severe myasthenia gravis developed after allogeneic hematopoietic stem cell transplantation with plasma exchange and rituximab. Pediatr Blood Cancer. 2014;61:928-930.

50. Yanagimachi M, Naruto T, Tanoshima R, et al. Influence of CYP3A5 and $A B C B 1$ gene polymorphisms on calcineurin inhibitor-related neurotoxicity after hematopoietic stem cell transplantation. Clin Transplant. 2010;24:855-861.

51. Köse $O$, Kürekçi $A E$, Safali $M$, Akin R, Köseoğlu V, Tezcan I. Development of in situ melanoma after allogeneic bone marrow transplantation in Griscelli syndrome type II. Pediatr Transplant. 2007;11: 792-795.

52. Ringden O, Brazauskas R, Wang Z, et al. Second solid cancers after allogeneic hematopoietic cell transplantation using reduced-intensity conditioning. Biol Blood Marrow Transplant. 2014;20:1777-1784.

53. Majhail NS, Brazauskas R, Rizzo JD, et al. Secondary solid cancers after allogeneic hematopoietic cell transplantation using busulfancyclophosphamide conditioning. Blood. 2011;117:316-322.

How to cite this article: Kuskonmaz B, Ayvaz D, Gokce M, et al. Hematopoietic stem cell transplantation in children with Griscelli syndrome: A single-center experience. Pediatr Transplant. 2017;e13040. https://doi.org/10.1111/petr.13040 